Case Report

\title{
A Case of Idiopathic Acute Pancreatitis in the First Trimester of Pregnancy
}

\author{
Tomomi Hara, Haruhiko Kanasaki, Aki Oride, Tomoko Ishihara, and Satoru Kyo \\ Department of Obstetrics and Gynecology, Shimane University School of Medicine, Izumo, Shimane 693-8501, Japan \\ Correspondence should be addressed to Haruhiko Kanasaki; kanasaki@med.shimane-u.ac.jp
}

Received 21 October 2015; Accepted 21 December 2015

Academic Editor: Svein Rasmussen

Copyright (C) 2015 Tomomi Hara et al. This is an open access article distributed under the Creative Commons Attribution License, which permits unrestricted use, distribution, and reproduction in any medium, provided the original work is properly cited.

\begin{abstract}
Acute pancreatitis is rare in pregnancy, with an estimated incidence of approximately 1 in 1000 to 1 in 10,000 pregnancies. Acute pancreatitis in pregnancy usually occurs in the third trimester. Here, we report a case of acute pancreatitis in the first trimester. A 36-year-old primigravida at 11 weeks of gestation complained of severe lower abdominal pain. The pain gradually worsened and migrated toward the epigastric region. She had no history of chronic alcoholism. Blood investigations showed elevated level of C-reactive protein $(9.58 \mathrm{mg} / \mathrm{dL})$, pancreatic amylase $(170 \mathrm{IU} / \mathrm{L})$, and lipase $(332 \mathrm{IU} / \mathrm{L})$. There was no gallstone and no abnormality in the pancreatic and biliary ducts on ultrasonography. Antinuclear antibody and IgG4 were negative and no evidence of hyperlipidemia or diabetes was found. There was also no evidence of viral infection. On the third day of hospitalization, she was diagnosed with severe acute pancreatitis on magnetic resonance imaging. Medical interventions were initiated with nafamostat mesilate and ulinastatin, and parenteral nutrition was administered through a central venous catheter. On the eighth day of hospitalization, her condition gradually improved with a decreased level of pancreatic amylase and the pain subsided. After conservative management, she did not have any recurrence during her pregnancy.
\end{abstract}

\section{Introduction}

The incidence of acute pancreatitis in pregnancy has been reported to be approximately 1 in 1000 to 1 in 10,000 pregnancies [1]. Previously, acute pancreatitis during pregnancy was a serious condition and the maternal mortality rate was high, but the mortality rate has recently decreased because diagnosis is reached earlier and maternal and neonatal intensive care have improved. However, studies have shown that cases of maternal death and fetal demise still occur $[2,3]$. More than $50 \%$ of cases during pregnancy are diagnosed in the third trimester, and acute pancreatitis is more common with advancing gestational age [4-6]. Here, we report a case of acute pancreatitis in the first trimester of pregnancy. The patient recovered and delivered a healthy baby at term.

\section{Case Report}

The patient was a 36-year-old woman who was gravida 0 para 0 . She had laparoscopic surgery 3 years ago for a ruptured endometriotic ovarian cyst at our hospital. She underwent intrauterine insemination and became pregnant. From 6 weeks of gestation, she was diagnosed with hyperemesis and was treated with herbal medicines prescribed by her physician and fluid infusions. When she was at 11 weeks of gestation, she was admitted to the hospital because of abdominal pain and vomiting that had begun after dinner, several hours before admission. She had neither vaginal bleeding nor diarrhea.

On admission, she was conscious with a body temperature of $37.0^{\circ} \mathrm{C}$, pulse of 84 beats $/ \mathrm{min}$, and a blood pressure of $108 / 61 \mathrm{mmHg}$. Ultrasound examination showed an intrauterine gestational sac with a fetus, and the fetal heart beat was regular. There was a $20.0 \times 9.0 \mathrm{~mm}$ hypoechoic lesion that was presumed to be subchorionic hemorrhage. There was neither ovarian tumor nor intra-abdominal fluid collections. She was provisionally diagnosed with a threatened miscarriage and subchorionic hemorrhage and was given isoxsuprine hydrochloride intravenously. However, the epigastric pain gradually worsened and was accompanied by an increase in body temperature to $38.9^{\circ} \mathrm{C}$ within several hours. To control the pain, she was given $15 \mathrm{mg}$ of pentazocine hydrochloride 
TABLE 1: Laboratory data of blood analysis on the next morning of hospitalization and additional data.

\begin{tabular}{|c|c|}
\hline \multicolumn{2}{|c|}{ Data on the next morning of hospitalization } \\
\hline WBC & $7020 / \mu \mathrm{L}$ \\
\hline $\mathrm{RBC}$ & $4.22 \times 10^{6} / \mu \mathrm{L}$ \\
\hline $\mathrm{Hb}$ & $13.1 \mathrm{~g} / \mathrm{dL}$ \\
\hline Hct & $36.70 \%$ \\
\hline Plt & $210 \times 10^{3} / \mu \mathrm{L}$ \\
\hline Neutrophils & $85.40 \%$ \\
\hline Eosinophils & $0.40 \%$ \\
\hline Lymphocytes & $7.90 \%$ \\
\hline РT\% & $76.00 \%$ \\
\hline PT-INR & 1.16 \\
\hline APTT & $33.6 \mathrm{sec}$ \\
\hline Fibrinogen & $477 \mathrm{mg} / \mathrm{dL}$ \\
\hline D-dimer & $11.0 \mu \mathrm{g} / \mathrm{mL}$ \\
\hline $\mathrm{TP}$ & $7.1 \mathrm{~g} / \mathrm{dL}$ \\
\hline Alb & $4.3 \mathrm{~g} / \mathrm{dL}$ \\
\hline T-Bil & $1.4 \mathrm{mg} / \mathrm{dL}$ \\
\hline AST & $14 \mathrm{IU} / \mathrm{L}$ \\
\hline ALT & $12 \mathrm{IU} / \mathrm{L}$ \\
\hline BUN & $5.7 \mathrm{mg} / \mathrm{dL}$ \\
\hline $\mathrm{Cr}$ & $0.37 \mathrm{mg} / \mathrm{dL}$ \\
\hline CRP & $9.58 \mathrm{mg} / \mathrm{dL}$ \\
\hline PCT & $0.36 \mathrm{ng} / \mathrm{mL}$ \\
\hline Amylase & $201 \mathrm{U} / \mathrm{L}$ \\
\hline P-amylase & $170 \mathrm{IU} / \mathrm{L}$ \\
\hline Lipase & $332 \mathrm{IU} / \mathrm{L}$ \\
\hline $\mathrm{LDH}$ & $180 \mathrm{U} / \mathrm{L}$ \\
\hline Alp & $166 \mathrm{U} / \mathrm{L}$ \\
\hline$\gamma$-GTP & $25 \mathrm{U} / \mathrm{L}$ \\
\hline ChE & 159 mg/dL \\
\hline Cholesterol & $136 \mathrm{mg} / \mathrm{dL}$ \\
\hline Triglyceride & $67 \mathrm{mg} / \mathrm{dL}$ \\
\hline LDL cholesterol & $70 \mathrm{mg} / \mathrm{dL}$ \\
\hline HDL cholesterol & $53 \mathrm{mg} / \mathrm{dL}$ \\
\hline FBS & $96 \mathrm{mg} / \mathrm{dL}$ \\
\hline \multicolumn{2}{|c|}{ Additional data } \\
\hline CA19-9 & $26 \mathrm{U} / \mathrm{mL}$ \\
\hline CEA & $1.2 \mathrm{ng} / \mathrm{mL}$ \\
\hline ANA & $>40$-fold \\
\hline IgG & 1124 mg/dL \\
\hline $\operatorname{IgG} 4$ & $58 \mathrm{mg} / \mathrm{mL}$ \\
\hline IgM & $55 \mathrm{mg} / \mathrm{dL}$ \\
\hline $\operatorname{IgA}$ & $243 \mathrm{mg} / \mathrm{dL}$ \\
\hline HBs antigen & $(-)$ \\
\hline HCV antibody & $(-)$ \\
\hline HIV antibody & $(-)$ \\
\hline TPHA & $(-)$ \\
\hline HTLV-1 & $(-)$ \\
\hline CMV-IgG & $>4$-fold \\
\hline
\end{tabular}

TABle 1: Continued.

\begin{tabular}{lc}
\hline CMV-IgM & 0.01 C.O.I \\
RS virus antibody & $>4$-fold \\
Anti-adenovirus antibody & 4 -fold \\
Mumps virus antibody IgG & $( \pm)$ \\
Mumps virus antibody IgM & $(-)$ \\
Anisakis larvae antibody & $(-)$ \\
Coxsackie virus B1 B6 & $>4$-fold \\
Anti-rubella antibody HI & 256 -fold \\
EBV-IgG & $(-)$ \\
\hline
\end{tabular}

WBC: white blood cells; RBC: red blood cells; Hb: hemoglobin; Hct: hematocrit; Plt: platelet; PT: prothrombin time; INR: international normalized ratio; APTT: activated partial thromboplastin time; TP: total protein; Alb: albumin; T-Bil: total bilirubin; AST: aspartate transaminase; ALT: alanine aminotransferase; BUN: blood urea nitrogen; $\mathrm{Cr}$ : creatinine; CRP: C-reactive protein; PCT: procalcitonin; LDH: lactate dehydrogenase; Alp: alkaline phosphatase; $\gamma$-GTP: $\gamma$-glutamyl transpeptidase; ChE: cholinesterase; FBS: fasting blood sugar; CA19-9: carbohydrate antigen 19-9; CEA: carcinoembryonic antigen; ANA: antinuclear antibody; TPHA: Treponemapallidum hemagglutination test; CMV: cytomegalovirus; C.O.I: cutoff index; HI: hemagglutination inhibition test; EBV: Epstein-Barr virus.

by an intramuscular injection. The possibility of appendicitis was excluded because there was no tenderness at McBurney's point.

On the day of admission, her white blood cell count (WBC) was $7480 / \mu \mathrm{L}$ and C-reactive protein (CRP) was $0.92 \mathrm{mg} / \mathrm{dL}$. The findings of blood analysis that was performed on the next morning of hospitalization are shown in Table 1 . WBC was still within the normal range $(7020 / \mu \mathrm{L})$ but CRP was raised to $9.58 \mathrm{mg} / \mathrm{dL}$. Her serum amylase was $201 \mathrm{U} / \mathrm{L}$ and pancreatic amylase and lipase were increased to $170 \mathrm{U} / \mathrm{L}$ and $332 \mathrm{IU} / \mathrm{L}$, respectively. No evidence of hyperlipidemia and diabetes was found. We suspected acute pancreatitis from her laboratory data, but ultrasonography showed no typical findings of acute pancreatitis such as pancreatic enlargement or inflammatory changes around the pancreas. Antinuclear antibody and IgG4 were negative. In addition, antibodies against viruses such as hepatitis $\mathrm{B}$ and $\mathrm{C}$ viruses, cytomegalovirus, respiratory syncytial virus, adenovirus, mumps virus, coxsackie viruses B1 to B6, and Epstein-Barr virus were all negative (Table 1). On the second day of hospitalization, her epigastric pain persisted and CRP had increased to $15.5 \mathrm{mg} / \mathrm{dL}$, so she underwent magnetic resonance imaging (MRI) examination.

MRI showed enlargement of the pancreatic body and the inflammation extended to the fat tissue, reaching beyond the lower pole of the kidney (Figure 1). Because computed tomography or a contrast study is not recommended for pregnant women, especially in the first trimester, the diagnosis of acute pancreatitis was made based on the findings of MRI.

Because there were no bile-pancreatic duct or lower bile duct stones, biliary pancreatitis was ruled out. We carried out conventional therapy including nutritional support, fluid infusion, antibiotics (meropenem hydrate), and protease inhibitors (nafamostat mesilate and ulinastatin). Her epigastric pain gradually reduced after the initiation of medical intervention for acute pancreatitis and some parameters on 

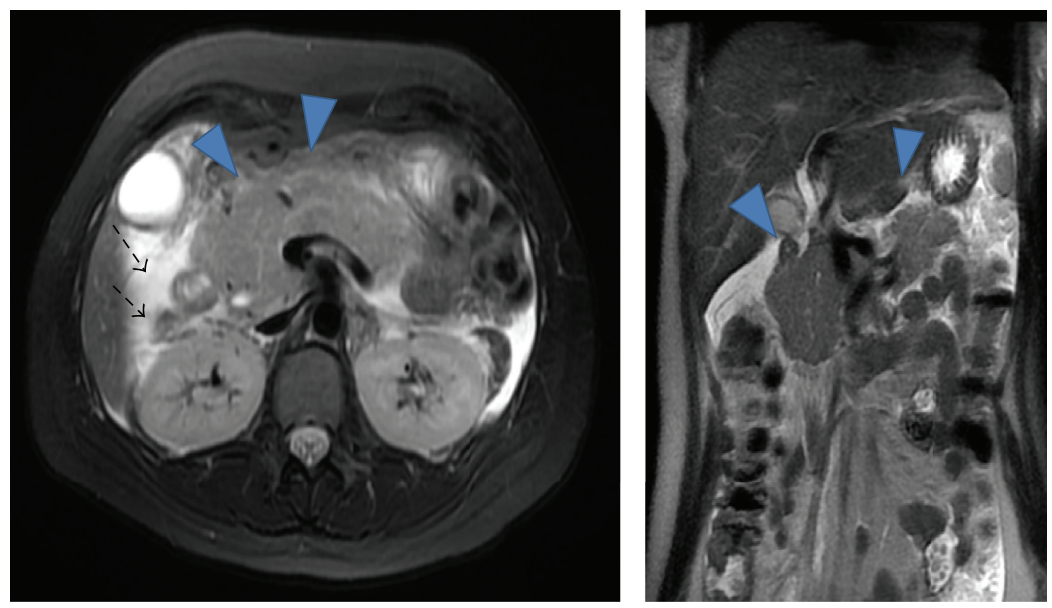

FIGURE 1: MRI T2W. $(\mathbf{\nabla})$ Enlargement of the pancreatic body. $(\rightarrow$ ) Inflammation of acute pancreatitis, extending to fat tissue and reaching beyond the lower pole of the kidney.

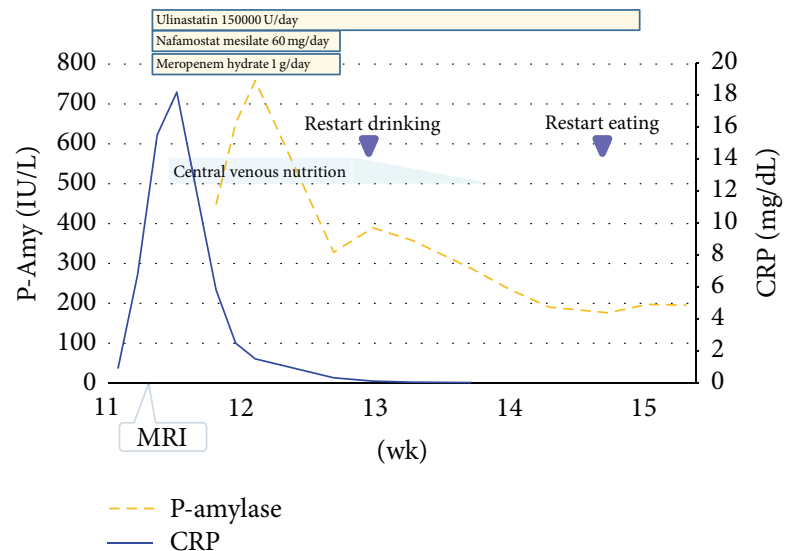

FIGURE 2: Clinography after hospitalization. Serum levels of CRP and pancreatic amylase (P-Amy) are shown. Medical interventions are shown in the graph.

blood examination improved after a few days. She completely recovered and was discharged at 19 weeks of gestation. Her serum amylase levels had dropped to $149 \mathrm{U} / \mathrm{L}$ at discharge. Her CRP levels, pancreatic amylase levels, and medical interventions during her hospitalization are summarized in Figure 2.

After conservative management, she did not have any recurrence of acute pancreatitis. At 22 weeks of gestation, she was diagnosed with threatened preterm labor triggered by per vaginal bleeding and was again hospitalized and underwent continuous intravenous infusion of ritodrine hydrochloride. At 37 weeks +2 days of gestation, cesarean section was performed because of marginal placenta previa. The baby's birth weight was $2694 \mathrm{~g}$ and the physical examination and clinical findings were normal.

\section{Discussion}

Acute pancreatitis is a common disease in the general population with an annual incidence of 27.7 per 100,000 .
Gallstones and alcohol abuse are the factors most strongly associated with acute pancreatitis in Japan. Because men often drink more alcohol than women, alcoholic-related pancreatitis appears more often in men. On the other hand, gallstone pancreatitis occurs more often in women because of the higher incidence of gallstones in women. Acute pancreatitis in pregnancy occurs infrequently and has a reported incidence of approximately 1 in 1,000 to 1 in 10,000 pregnancies [1]. The incidence of acute pancreatitis increases with gestational age; $53 \%$ to $79 \%$ of these cases were diagnosed in the third trimester $[3,7]$. The incidence of acute pancreatitis in the first trimester is lower than that in the third trimester and its incidence has been reported to be $19 \%$ [7] or $29 \%$ [8]. Tang et al. reported that, among pregnant women with pancreatitis, the percentage of women who reached term was the lowest for those who developed pancreatitis in the first trimester and these women were at highest risk of fetal loss and preterm delivery because the fetus in the first trimester is vulnerable [8]. In contrast, Legro and Laifer reported that the prognosis for pregnancy outcome in the first trimester was good [9]. Indeed, reaching the correct diagnosis of acute pancreatitis in the first trimester is more difficult than in the third trimester of pregnancy. The symptoms of acute pancreatitis such as vomiting and abdominal pain are similar to symptoms of hyperemesis or threatened abortion. When acute pancreatitis becomes worse and ascites is pooled in the pelvic cavity, it is difficult to distinguish it from ectopic pregnancy or ruptured corpus luteal cyst. We first assumed that abdominal pain was caused by uterine contraction and vomiting was caused by hyperemesis gravidarum; thus, we diagnosed her with threatened abortion. However, because abdominal pain was not improved after hospitalization, gastrointestinal disease was suspected and the measurement of amylase levels enabled us to reach the diagnosis of pancreatitis.

Compared with the nonpregnant general population, acute pancreatitis in pregnant women is more likely to be associated with cholelithiasis, while hyperlipidemia and alcohol abuse as causes are less frequent [10]. Previous studies 
showed that $65 \%$ or more cases of acute pancreatitis in pregnancy were associated with cholelithiasis $[2,4,11]$.

Women are likely to have gallstones during pregnancy. Cholesterol secretion in the hepatic bile increases in the second and third trimester of pregnancy, and the increase in the percentage of cholic acid leads to the increase of supersaturated bile. Moreover, elevated levels of progesterone during pregnancy induce smooth muscle relaxation of the gallbladder, which causes bile stasis. Increased cholesterol concentration in the hepatic bile and decreased emptying of the gallbladder lead to the retention of cholesterol crystals, and gallstones eventually form. In addition, in the third trimester, an enlarged uterus and increased intra-abdominal pressure on the biliary duct increase the risk of acute pancreatitis $[1,8,12]$. On the other hand, pancreatitis induced by hyperlipidemia is also observed during pregnancy. In this situation, serum triglyceride increases above $1000 \mathrm{mg} / \mathrm{dL}$ because of the increased secretion of triglycerides, and production of very low-density lipoproteins is induced by elevated levels of estrogens. It is reported that hyperlipidemic pancreatitis in pregnancy occurs more frequently and is more severe in the setting of familial hyperlipidemia [13]. In our case, the patient was not a habitual alcohol drinker. Also, there was no definite evidence of intra- or extrahepatic duct dilatation, gallstones, or pancreaticobiliary maljunction.

Viral infection could be a cause of acute pancreatitis. We first suspected viral infection because antinuclear antibody and IgG4 were negative, and no evidence of hyperlipidemia or diabetes was found. However, virus antibodies such as hepatitis $\mathrm{B}$ or $\mathrm{C}$ virus, cytomegalovirus, respiratory syncytial virus, adenovirus, mumps virus, coxsackie viruses $\mathrm{B} 1$ to $\mathrm{B} 6$, and Epstein-Barr virus were all negative. The cause of her acute pancreatitis remains unclear; thus, we diagnosed her with idiopathic acute pancreatitis. Geng et al. reported that $11.1 \%$ of patients with acute pancreatitis during pregnancy had idiopathic disease [14].

Although the maternal and fetal mortality rates in acute pancreatitis are declining because of earlier diagnosis and advances in treatment options, fetal loss could still occur. Hernandez et al. reported that $4.7 \%$ of pregnant women lost their fetus, based on experience of a single center over a 10-year period [15]. The risks to the fetus during acute pancreatitis are not only in utero fetal death but also threatened preterm labor and prematurity. Termination of pregnancy could be an option to cure acute pancreatitis during pregnancy.

Acute pancreatitis in pregnancy is rare, but this disease could be the cause of acute abdominal pain and manifest with emesis-like symptoms during the first trimester. In our case, analysis of amylase levels and MRI helped us to reach the correct diagnosis. We should consider this disease when pregnant women complain of severe abdominal pain with symptoms related to the alimentary tract.

\section{References}

[1] C. S. Pitchumoni and B. Yegneswaran, "Acute pancreatitis in pregnancy," World Journal of Gastroenterology, vol. 15, no. 45, pp. 5641-5646, 2009.

[2] C. Qihui, Z. Xiping, and D. Xianfeng, "Clinical study on acute pancreatitis in pregnancy in 26 cases," Gastroenterology Research and Practice, vol. 2012, Article ID 271925, 5 pages, 2012.

[3] D.-L. Zhang, Y. Huang, L. Yan, A. Phu, X. Ran, and S.-S. Li, "Thirty-eight cases of acute pancreatitis in pregnancy: a 6year single center retrospective analysis," Journal of Huazhong University of Science and Technology (Medical Science), vol. 33, no. 3, pp. 361-367, 2013.

[4] R. Vilallonga, A. Calero-Lillo, R. Charco, and J. Balsells, "Acute pancreatitis during pregnancy, 7-year experience of a terciary referral center," Cirugía Española, vol. 92, no. 7, pp. 468-471, 2014.

[5] P. Charlet, V. Lambert, and G. Carles, "Acute pancreatitis and pregnancy: cases study and literature review," Journal de Gynécologie, Obstétrique et Biologie de la Reproduction, vol. 44, no. 6, pp. 541-549, 2015.

[6] S. K. Juneja, P. Tandon, S. Virk, V. Bindal, and S. Gupta, "Acute pancreatitis in pregnancy: a treatment paradigm based on our hospital experience," International Journal of Applied and Basic Medical Research, vol. 3, no. 2, pp. 122-125, 2013.

[7] K. D. Ramin, S. M. Ramin, S. D. Richey, and F. G. Cunningham, "Acute pancreatitis in pregnancy," American Journal of Obstetrics and Gynecology, vol. 173, no. 1, pp. 187-191, 1995.

[8] S. J. Tang, E. Rodriguez-Frias, S. Singh et al., "Acute pancreatitis during pregnancy," Clinical Gastroenterology and Hepatology, vol. 8, no. 1, pp. 85-90, 2010.

[9] R. S. Legro and S. A. Laifer, "First-trimester pancreatitis. Maternal and neonatal outcome," Journal of Reproductive Medicine, vol. 40, no. 10, pp. 689-695, 1995.

[10] A. Gilbert, V. Patenaude, and H. A. Abenhaim, "Acute pancreatitis in pregnancy: a comparison of associated conditions, treatments and complications," Journal of Perinatal Medicine, vol. 42, no. 5, pp. 565-570, 2014.

[11] J. Jin, Y. Yu, M. Zhong, and G. Zhang, "Analyzing and identifying risk factors for acute pancreatitis with different etiologies in pregnancy," The Journal of Maternal-Fetal \& Neonatal Medicine, vol. 28, no. 3, pp. 267-271, 2015.

[12] M. Pandey and V. K. Shukla, "Lifestyle, parity, menstrual and reproductive factors and risk of gallbladder cancer," European Journal of Cancer Prevention, vol. 12, no. 4, pp. 269-272, 2003.

[13] G. Lippi, A. Albiero, M. Montagnana et al., "Lipid and lipoprotein profile in physiological pregnancy," Clinical Laboratory, vol. 53, no. 3-4, pp. 173-177, 2007.

[14] Y. Geng, W. Li, L. Sun, Z. Tong, N. Li, and J. Li, "Severe acute pancreatitis during pregnancy: eleven years experience from a surgical intensive care unit," Digestive Diseases and Sciences, vol. 56, no. 12, pp. 3672-3677, 2011.

[15] A. Hernandez, M. S. Petrov, D. C. Brooks, P. A. Banks, S. W. Ashley, and A. Tavakkolizadeh, "Acute pancreatitis and pregnancy: a 10-year single center experience," Journal of Gastrointestinal Surgery, vol. 11, no. 12, pp. 1623-1627, 2007.

\section{Conflict of Interests}

No author has any potential conflict of interests. 


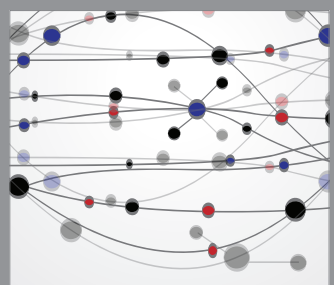

The Scientific World Journal
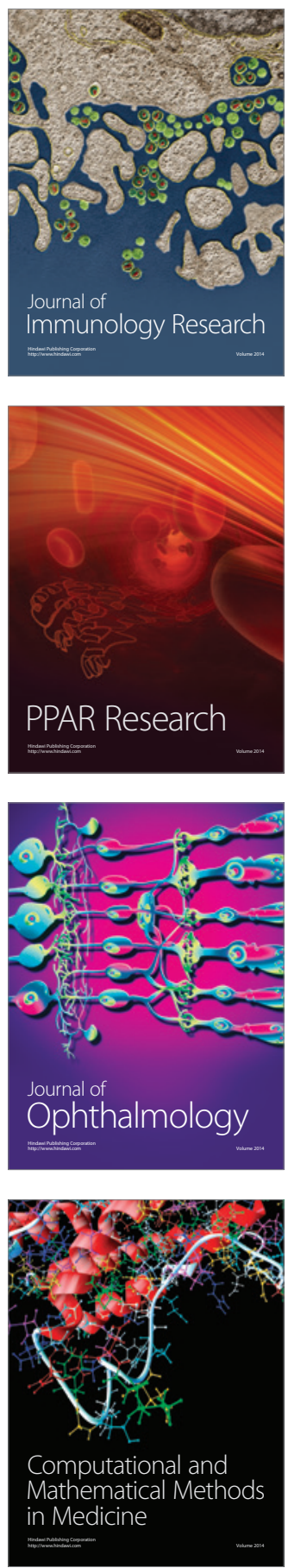

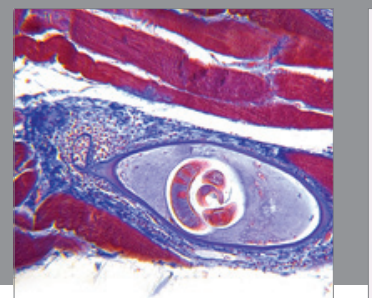

Gastroenterology

Research and Practice
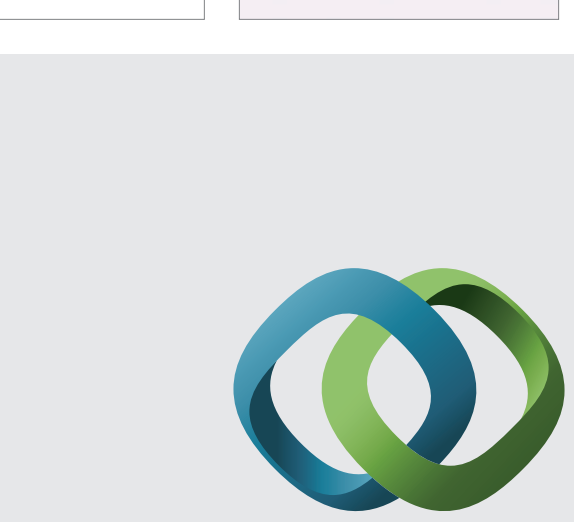

\section{Hindawi}

Submit your manuscripts at

http://www.hindawi.com
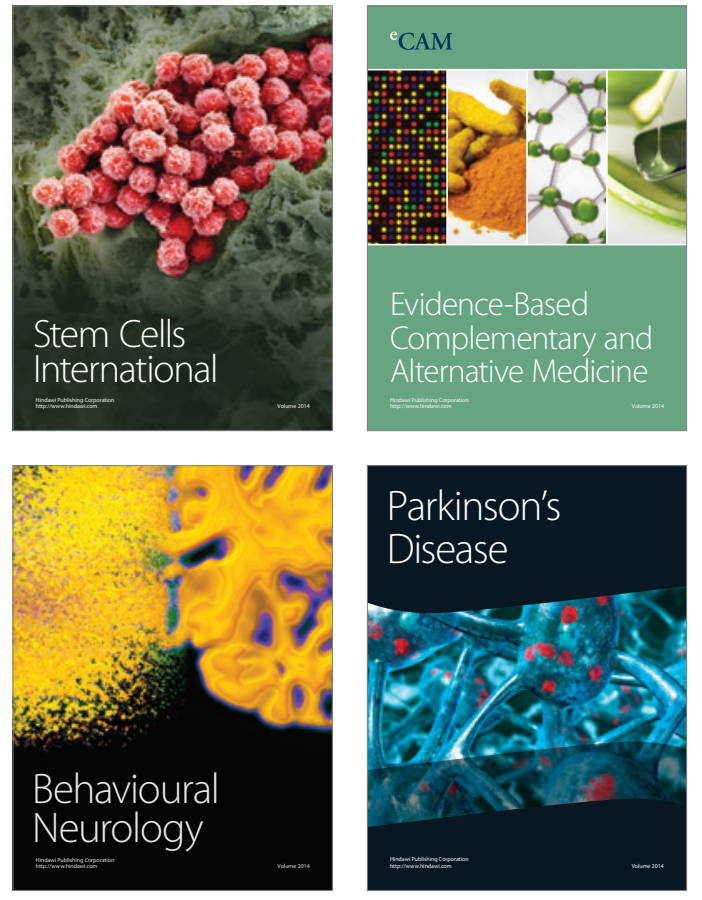
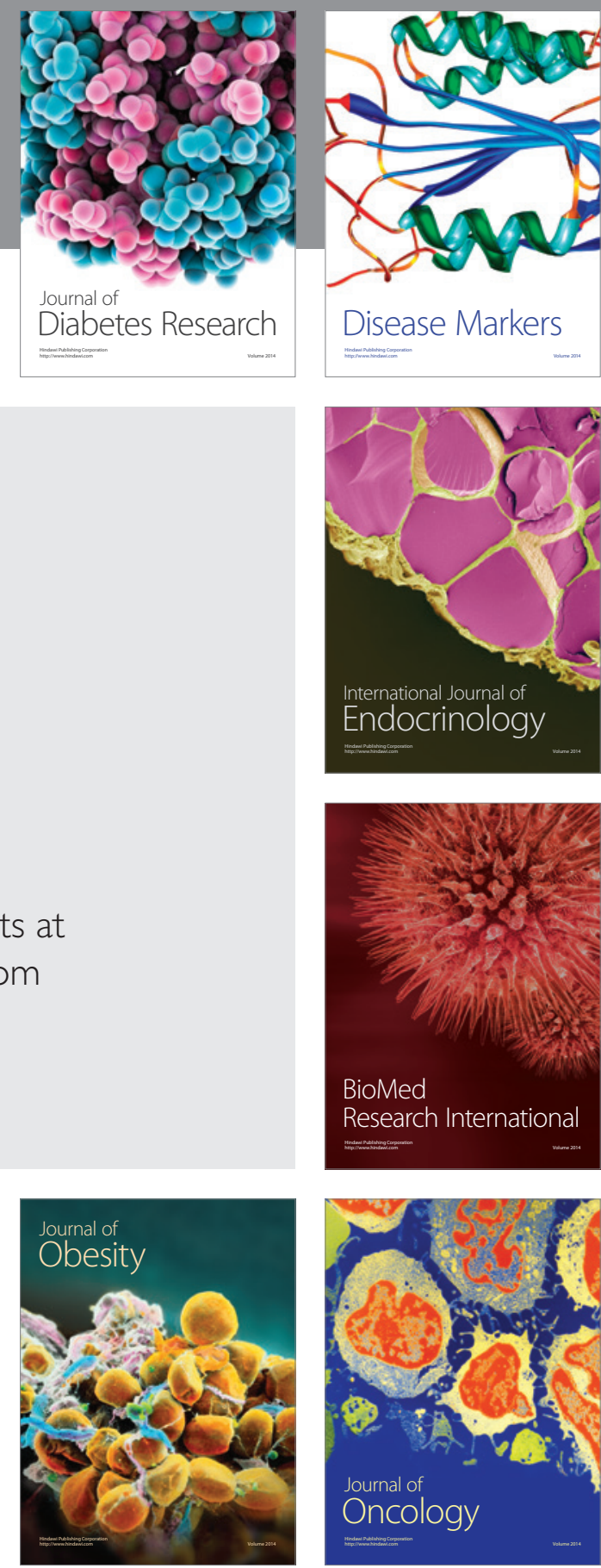

Disease Markers
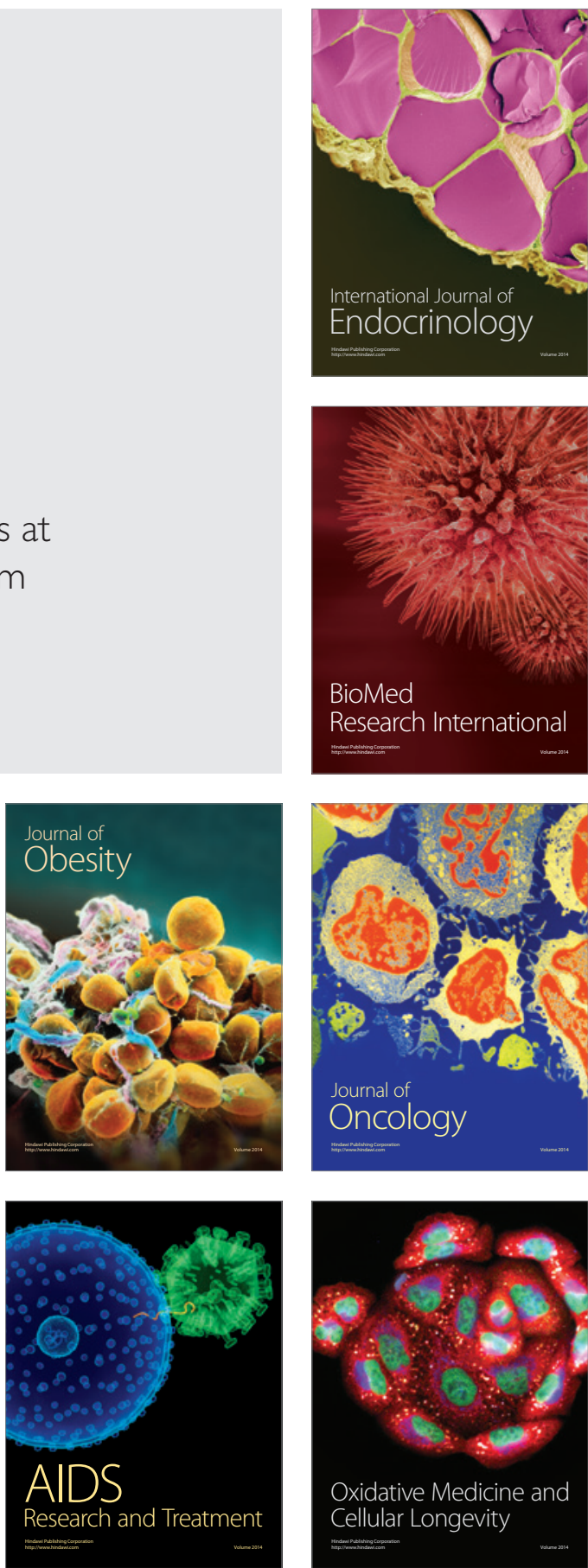